\title{
Aromatic Aldehydes Production by Oxidative Degradation of Solid Residue Derived from Pine Waste Hydrolysis Coupling Acetylation
}

\author{
Siyu $\mathrm{Nie}^{1}$, Leichang $\mathrm{Cao}^{1,2, *}$ \\ ${ }^{1}$ Miami College, Henan University, Kaifeng 475004, China \\ ${ }^{2}$ Department of Environmental Science and Engineering, Fudan University, Shanghai 200433, China
}

\begin{abstract}
Xylose and cellulose acetate were prepared by hydrolysis and acetylation of hemicellulose and cellulose in landscaping biomass waste (pine) by dilute acid hydrolysis and acetylation, respectively. The obtained solid residue was rich in lignin that mainly contains three phenylpropane structural units and can be used to prepare aromatic chemicals under hydrothermal conditions. In this work, the synthesis of high value-added aromatic aldehydes (vanillin, syringaldehyde, and p-hydroxybenzaldehyde) from the solid residue (rich in lignin) by mild catalytic oxidation was studied. The oxidation degradation of the solid residue in $\mathrm{NaOH}$ solution to produce aromatic aldehydes was investigated by single factor experiment. The optimum reaction conditions were obtained as follows: $175^{\circ} \mathrm{C}, 90 \mathrm{~min}, 3.0 \mathrm{~g}$ solid residue, $100.0 \mathrm{ml} \mathrm{NaOH}$ solution (concentration of $2.0 \mathrm{~mol} / \mathrm{L}$ ), and oxygen pressure of $1.5 \mathrm{MPa}$. Under these conditions, the total yield of aromatic aldehydes from pine branch residue was $23.8 \mathrm{wt} \%$.
\end{abstract}

\section{Background}

Greening waste refers to the falling branches, fallen leaves, flower decay, grass debris, tree and shrub cutting and other plant residues produced by human pruning or natural withering, which is also called green waste garbage or garden waste by some researchers $[1,2]$. Wet oxidation refers to the process in which organic or inorganic substances in aqueous solution or suspension are oxidized by oxidants at higher temperature and pressure [3]. The operating temperature and pressure range are $100{ }^{\circ} \mathrm{C} \sim 320{ }^{\circ} \mathrm{C}$ and $0.5 \mathrm{MPa} \sim 20 \mathrm{MPa}$ [4]. Although some studies on wet oxidation of lignin have been applied to wastewater treatment [5-7], others have focused on the production of organic acids through lignin oxidation. It has been reported that alkali lignin and organic solvent lignin can produce $0.45 \mathrm{~g} / \mathrm{g}$ and $0.20 \mathrm{~g} / \mathrm{g}$ organic acids at different temperatures $[8,9]$. However, most of the wet oxidative degradation of lignin is used to produce aromatic aldehydes, such as vanillin (VLA), syringaldehyde (SA) and phydroxybenzaldehyde (PHBA). These compounds have many applications, especially vanillin is widely used in food, cosmetics and pharmaceutical industries as condiments and spices. However, among these products, only vanillin has been industrialized. In this work, the synthesis of high value-added aromatic aldehydes (vanillin, syringaldehyde, and p-hydroxybenzaldehyde) from the solid residue (rich in lignin) by mild catalytic oxidation was studied.

\section{Experimental}

\subsection{Pretreatment of greening waste}

The discarded pine branches were collected from Handan Road Campus of Fudan University in Shanghai, China. At that time, the collection time was just the time when the green pruning workers pruned the branches and leaves in spring, and all the branches and leaves were just trimmed by the workers. After the raw materials are collected, they are dried in an oven at $105^{\circ} \mathrm{C}$ for 8 hours, and then mechanically crushed through a 40 mesh sieve, and the screened samples are kept for standby.

\subsection{Basic operation steps for preparation of aromatic aldehydes by catalytic oxidation of cellulose acetate solid residue}

$3.0 \mathrm{~g}$ of cellulose acetate solid residue was used and 100 $\mathrm{ml}$ sodium hydroxide solution with concentration of 2.0 $\mathrm{mol} / \mathrm{L}$ and the addition of $0.02 \mathrm{~g} \mathrm{CuSO}_{4}$ under oxygen pressure of $1.5 \mathrm{MPa}$ at $175^{\circ} \mathrm{C}$ for $90 \mathrm{~min}$. After reaction, the reaction liquid was cooled and acidified with $1 \mathrm{~mol} / \mathrm{L}$ hydrochloric acid to $\mathrm{pH}=3.5$. After filtration, the filter cake is washed, dried, and weighed, and the content of filter cake is determined according to the NREL standard method. Then the conversion rate of lignin (lignin conversion rate $=1-\mathrm{m} / \mathrm{M}$ ) was calculated according to the lignin mass (m) in the original cellulose acetate solid

\footnotetext{
* Corresponding author: clch666@163.com
} 
residue. The filtrate and washing solution were combined and extracted by $300 \mathrm{~mL}$ chloroform in three times. The content of aromatic aldehydes in the extraction solution was determined by GC-MS external standard method (e.g., Fig. 1 and 2), and the yield of aromatic aldehyde was finally calculated based on $\mathrm{M}$.

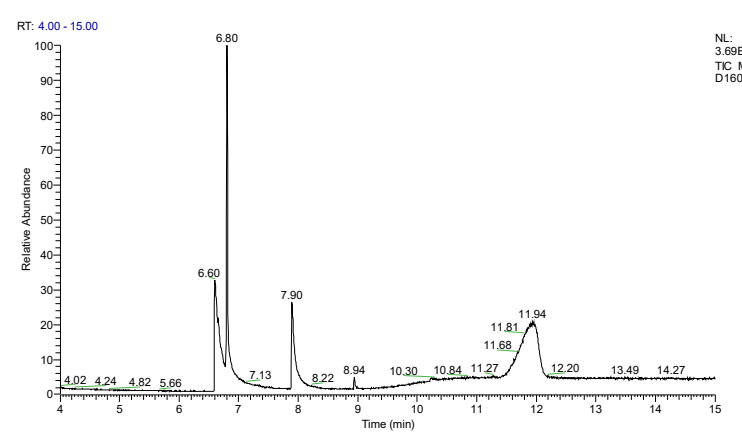

Fig. 1. TIC spectrum of cellulose acetate solid residue catalytic oxidation products (conditions: $2.0 \mathrm{~mol} / 1 \mathrm{NaOH}$ solution 100.0ml, $\left.1.5 \mathrm{MPa}, 175^{\circ} \mathrm{C}, 90 \mathrm{~min}\right)$.

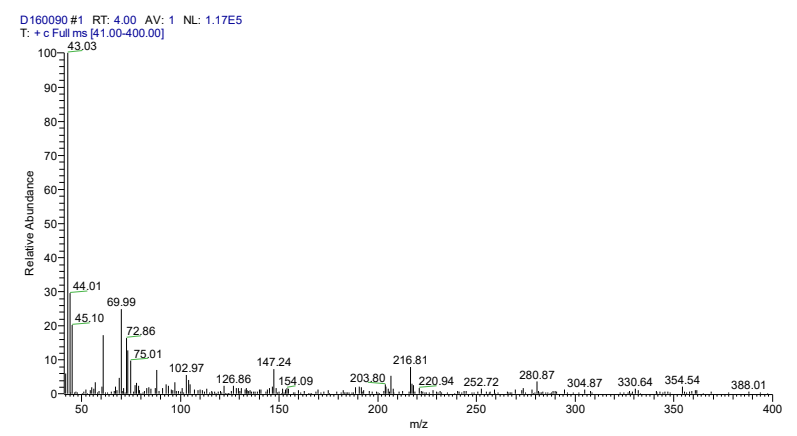

Fig. 2. Mass spectrum of cellulose acetate solid residue catalytic oxidation products (conditions: $2.0 \mathrm{~mol} / 1 \mathrm{NaOH}$ solution $\left.100.0 \mathrm{ml}, 1.5 \mathrm{MPa}, 175^{\circ} \mathrm{C}, 90 \mathrm{~min}\right)$.

\section{Results and Discussion}

\subsection{Effect of catalyst types}

The effects of different catalysts on the preparation of aromatic aldehydes from cellulose acetate solid residue under the conditions of $3.0 \mathrm{~g}$ (cellulose acetate rsm16ca), $2.0 \mathrm{~mol} / \mathrm{L} \mathrm{NaOH}$ solution $100.0 \mathrm{ml}, 1.5 \mathrm{MPa}$, $175{ }^{\circ} \mathrm{C}$ and $90 \mathrm{~min}$ were investigated. The results are shown in Table 1.

Table 1. Effect of catalyst types on catalytic oxidation of cellulose acetate solid residue.

\begin{tabular}{|c|c|c|c|c|c|}
\hline Catalyst & $\begin{array}{c}\text { VLA } \\
(\mathrm{g})\end{array}$ & $\begin{array}{c}\mathrm{SA} \\
(\mathrm{g})\end{array}$ & $\begin{array}{c}\text { PHB } \\
\text { A } \\
(\mathrm{g})\end{array}$ & $\begin{array}{c}\text { Lignin } \\
\text { Conversion } \\
\text { rate }(\%)\end{array}$ & $\begin{array}{c}\text { Total } \\
\text { Yield } \\
(\%)\end{array}$ \\
\hline $\mathrm{ZnCl}_{2}$ & 0.026 & 0.017 & 0.010 & 77.1 & 10.6 \\
\hline $\mathrm{FeCl}_{3}$ & 0.042 & 0.034 & 0.016 & 85.2 & 18.4 \\
\hline
\end{tabular}

\begin{tabular}{|l|l|l|l|l|l|}
\hline $\mathrm{CuNO}_{3}$ & 0.065 & 0.029 & 0.020 & 98.7 & 22.8 \\
\hline $\mathrm{CuSO}_{4}$ & 0.065 & 0.032 & 0.022 & 100 & 23.8 \\
\hline
\end{tabular}

It can be seen from the above Table that different catalysts have different effects on the yield of aromatic aldehydes. $\mathrm{CuSO}_{4}$ is the best catalyst, and the total yield of aromatic aldehydes is as high as $24.4 \%$, and the effect of iron salt is also good. This may be due to the promotion of oxidative degradation of wood in the process of electron gain and loss of transition metal salt ions [10].

\subsection{Effect of $\mathrm{NaOH}$ solution concentration on reaction}

Without changing other conditions, $\mathrm{CuSO}_{4}$ was selected as catalyst to investigate the effect of $\mathrm{NaOH}$ solution concentration on the yield of aromatic aldehydes. The experimental results are listed in Table 2.

Table 2. Effect of $\mathrm{NaOH}$ concentration.

\begin{tabular}{|c|c|c|c|c|c|}
\hline $\begin{array}{c}\mathrm{NaOH} \\
(\mathrm{mol} / \mathrm{L})\end{array}$ & $\begin{array}{c}\mathrm{VLA} \\
(\mathrm{g})\end{array}$ & $\begin{array}{c}\mathrm{SA} \\
(\mathrm{g})\end{array}$ & $\begin{array}{c}\text { PHB } \\
\mathrm{A})\end{array}$ & $\begin{array}{c}\text { Lignin } \\
\text { Conversion } \\
\text { rate }(\%)\end{array}$ & $\begin{array}{c}\text { Total } \\
\text { Yield } \\
(\%)\end{array}$ \\
\hline 1.6 & 0.041 & 0.021 & 0.017 & 86.3 & 15.8 \\
\hline 2.0 & 0.065 & 0.032 & 0.022 & 100 & 23.8 \\
\hline 2.4 & 0.062 & 0.030 & 0.019 & 100 & 22.2 \\
\hline 2.8 & 0.045 & 0.024 & 0.018 & 100 & 17.4 \\
\hline
\end{tabular}

It can be seen from the above table that too high or too low alkali concentration is not conducive to the formation of aromatic aldehydes. Properly increasing the alkali concentration is conducive to the degradation of lignin, and its conversion and product yield increase correspondingly. However, when the concentration of $\mathrm{NaOH}$ is too high, the side effects will increase correspondingly, leading to the decrease of aromatic aldehyde yield [11,12]. Therefore, $2.0 \mathrm{~mol} / \mathrm{L}$ is the optimal concentration of $\mathrm{NaOH}$ solution.

\subsection{Effect of catalyst dosage}

Without changing other reaction conditions, the yield of aromatic aldehydes was investigated with different amount of $\mathrm{CuSO}_{4}$. The experimental results are shown in Table 3.

Table 3. Effect of catalyst dosage.

\begin{tabular}{|c|c|c|c|c|c|}
\hline $\begin{array}{c}\text { CuSO } \\
4 \\
(\mathrm{~g})\end{array}$ & $\begin{array}{c}\text { VLA } \\
(\mathrm{g})\end{array}$ & $\begin{array}{c}\text { SA } \\
(\mathrm{g})\end{array}$ & $\begin{array}{c}\text { PHBA } \\
(\mathrm{g})\end{array}$ & $\begin{array}{c}\text { Lignin } \\
\text { Conversio } \\
\text { n rate }(\%)\end{array}$ & $\begin{array}{c}\text { Total } \\
\text { Yield } \\
(\%)\end{array}$ \\
\hline 0 & 0.022 & 0.011 & 0.005 & 33.2 & 7.6 \\
\hline
\end{tabular}




\begin{tabular}{|l|l|l|l|l|l|}
\hline 0.01 & 0.034 & 0.014 & 0.010 & 66.7 & 11.6 \\
\hline 0.02 & 0.065 & 0.032 & 0.022 & 100 & 23.8 \\
\hline 0.03 & 0.039 & 0.021 & 0.013 & 100 & 14.6 \\
\hline
\end{tabular}

As shown in the above table, when $\mathrm{CuSO}_{4}$ dosage is $0.02 \mathrm{~g}(4 \mathrm{wt} \%)$, the yield of aromatic aldehydes is the highest. Excessive $\mathrm{Cu}^{2+}$ can cause excessive oxidation of phenylpropane structure in lignin to form acid compounds [13]. Therefore, the optimal dosage of $\mathrm{CuSO}_{4}$ is $0.02 \mathrm{~g}$.

\subsection{Effect of the amount of cellulose acetate solid residue}

The influence of the amount of cellulose acetate solid residue on the preparation of aromatic aldehydes by catalytic oxidation degradation of cellulose acetate solid residue was investigated under the condition of other fixed conditions unchanged. The experimental results are shown in Table 4.

Table 4. Effect of solid residue amount on catalytic oxidation of cellulose acetate solid residue.

\begin{tabular}{|c|c|c|c|c|c|}
\hline $\begin{array}{c}\text { Solid } \\
\text { residue } \\
(\mathrm{g})\end{array}$ & $\begin{array}{c}\text { VLA } \\
(\mathrm{g})\end{array}$ & $\begin{array}{c}\text { SA } \\
(\mathrm{g})\end{array}$ & $\begin{array}{c}\text { PHB } \\
\mathrm{A} \\
(\mathrm{g})\end{array}$ & $\begin{array}{c}\text { Lignin } \\
\text { Conversion } \\
\text { rate }(\%)\end{array}$ & $\begin{array}{c}\text { Total } \\
\text { Yield } \\
(\%)\end{array}$ \\
\hline 1.0 & 0.021 & 0.010 & 0.006 & 100 & 7.4 \\
\hline 2.0 & 0.033 & 0.018 & 0.015 & 100 & 13.2 \\
\hline 3.0 & 0.065 & 0.032 & 0.022 & 100 & 23.8 \\
\hline 4.0 & 0.058 & 0.029 & 0.021 & 96.2 & 21.6 \\
\hline
\end{tabular}

It can be seen from the above table that the yields of aromatic aldehydes are significantly different under different solid residues. When the amount of cellulose acetate solid residue is small, all lignin can be reacted, but the yield of aromatic aldehyde is obviously low. When the solid residue amount is $3.0 \mathrm{~g}$, the yield reaches the maximum value of $23.8 \%$. If the amount of cellulose acetate is increased continuously, the lignin can not be completely transformed, and the yield is slightly reduced. Therefore, the optimal amount of cellulose acetate solid residue is $3.0 \mathrm{~g}$.

\subsection{Effect of oxygen pressure}

It can be seen from table 5 that under low oxygen pressure (no more than 1.2 $\mathrm{MPa}$ ), the lignin in solid residue can not be completely converted, and the yield of aromatic aldehyde is also low; when the oxygen pressure reaches $1.5 \mathrm{MPa}$, the conversion rate of lignin reaches $100 \%$, and the yield of aromatic aldehydes reaches the maximum value; if the pressure continues to increase, the aromatic aldehydes will decrease, which may be due to the deep oxidation of aromatic aldehydes into acids by excessive oxygen $[14,15]$.

Table 5. Effect of oxygen pressure on catalytic oxidation of cellulose acetate solid residue.

\begin{tabular}{|c|c|c|c|c|c|}
\hline $\begin{array}{c}\mathrm{O}_{2} \\
(\mathrm{MPa})\end{array}$ & $\begin{array}{c}\text { VLA } \\
(\mathrm{g})\end{array}$ & $\begin{array}{c}\mathrm{SA} \\
(\mathrm{g})\end{array}$ & $\begin{array}{c}\text { PHBA } \\
(\mathrm{g})\end{array}$ & $\begin{array}{c}\text { Lignin } \\
\text { Conversion } \\
\text { rate }(\%)\end{array}$ & $\begin{array}{c}\text { Total } \\
\text { Yield } \\
(\%)\end{array}$ \\
\hline 0.9 & 0.028 & 0.015 & 0.011 & 88.2 & 10.8 \\
\hline 1.2 & 0.044 & 0.023 & 0.016 & 93.5 & 16.6 \\
\hline 1.5 & 0.065 & 0.032 & 0.022 & 100 & 23.8 \\
\hline 1.8 & 0.059 & 0.034 & 0.020 & 100 & 22.6 \\
\hline
\end{tabular}

\section{Conclusion}

The oxidation degradation of cellulose acetate solid residue in $\mathrm{NaOH}$ solution to produce aromatic aldehydes was investigated by single factor test. The optimum reaction conditions were obtained as follows: cellulose acetate solid residue $3.0 \mathrm{~g}$, concentration of $2.0 \mathrm{~mol} / \mathrm{l}$ $\mathrm{NaOH}$ solution $100.0 \mathrm{ml}$, oxygen pressure $1.5 \mathrm{MPa}$, reaction temperature $175{ }^{\circ} \mathrm{C}$, reaction time $90 \mathrm{~min}$. Under this condition, the total yield of aromatic aldehydes (vanillin, syringaldehyde, phydroxybenzaldehyde) of pine branch was $23.8 \mathrm{wt} \%$.

\section{Acknowledgement}

The authors are thankful for the financial support from the National Key Technology Support Program (No. 2015BAD15B06), and the National Natural Science Foundation of China (No.583 21407027, 21577025). The authors are also grateful for the provision of a scholarship by Shanghai Tongji Gao Tingyao Environmental Science \& Technology Development Foundation. Lastly, the authors thank anonymous reviewers for fruitful suggestions.

\section{References}

1. Y. Cao, N. Wang, X. He, H.R. Li, L.N. He, Acs Sustain Chem Eng, 6 (2018)

2. X.N. Yu, Z.Q. Wei, Z.X. Lu, H.S. Pei, H.L. Wang, Bioresource Technol, 291 (2019)

3. V.E. Tarabanko, N. Tarabanko, Int J Mol Sci, 18 (2017)

4. A. Das, A. Rahimi, A. Ulbrich, M. Alherech, A.H. Motagamwala, A. Bhalla, L.D. Sousa, V. Balan, J.A. Dumesic, E.L. Hegg, B.E. Dale, J. Ralph, J.J. Coon, S.S. Stahl, Acs Sustain Chem Eng, 6 (2018)

5. L. Das, P. Kolar, J.A. Osborne, R.R. Sharma-Shivappa, J.J. Classen, T Asabe, 59 (2016)

6. H.B. Deng, H. Zhang, Z.L. Wu, X.Z. Tian, X. Jiang, W.M. Guo, Bioresources, 15 (2020) 
7. T.N. Tana, Z.Y. Zhang, J. Beltramini, H.Y. Zhu, K. Ostrikov, J. Bartley, W. Doherty, Green Chem, 21 (2019)

8. A. Dominguez-Gonzalez, R. Hernandez-Soto, J.M. Salgado-Roman, A.N. Ardila-Arias, J.A. Hernandez-Maldonado, Agrociencia-Mexico, 52 (2018)

9. S. Stahl, Abstr Pap Am Chem S, 255 (2018)

10. C.X. Lan, H.X. Fan, Y.Y. Shang, D.Y. Shen, G. Li, Sustain Energ Fuels, 4 (2020)

11. M.R.C. Fernandes, X.M. Huang, H.C.L. Abbenhuis, E.J.M. Hensen, Int J Biol Macromol, 123 (2019)

12. L. Pistone, G. Ottolina, S. De, A.A. Romero, L.O. Martins, R. Luque, Chemsuschem, 9 (2016)

13. T. Hosoya, K. Yamamoto, H. Miyafuji, T. Yamada, Rsc Adv, 10 (2020)

14. L. Li, S.T. Yu, C.X. Xie, F.S. Liu, S.W. Liu, K. Li, Z.Y. Dong, Acs Sustain Chem Eng, 5 (2017)

15. X.J. Lu, X.F. Zhou, Z.L. Zhu, Y.L. Sun, K. Tang, F.H. Lei, Z.G. Liu, T. Wang, Drewno, 62 (2019) 